\title{
Configurações
}

Revista de sociologia

\section{Um teatro de intensidades: subtração dos elementos do poder na cena teatral contemporânea}

A theater of intensities: subtraction of the elements of power in the contemporary theatrical scene

Un théâtre d'intensités: soustraction des éléments de pouvoir dans la scène théâtrale contemporaine

\section{Arthur Belloni}

\section{OpenEdition}

\section{Journals}

Edição electrónica

URL: http://journals.openedition.org/configuracoes/5822

DOI: $10.4000 /$ configuracoes.5822

ISSN: 2182-7419

Editora

Centro de Investigação em Ciências Sociais

Edição impressa

Paginação: 83-100

ISSN: 1646-5075

\section{Refêrencia eletrónica}

Arthur Belloni, « Um teatro de intensidades: subtração dos elementos do poder na cena teatral

contemporânea », Configurações [Online], 22 | 2018, posto online no dia 21 dezembro 2018, consultado o 20 abril 2019. URL : http://journals.openedition.org/configuracoes/5822 ; DOI : 10.4000/

configuracoes.5822 
Belloni, Arthur - Um teatro de intensidades: subtração dos elementos do poder na cena teatral contemporânea. Configurações, vol. 22, 2018, pp. 83-100.

\title{
Um teatro de intensidades: subtração dos elementos do poder na cena teatral contemporânea
}

ARTHUR BELLONI*

Universidade Federal de Santa Maria (UFSM-Brasil)

\begin{abstract}
Resumo
Partindo de alguns aspectos ligados à concepção de teatro menor (associada, por Deleuze, à operação cênica de Carmelo Bene) e, também, à noção de teatro pré-trágico (sugerida por R. Castellucci), o artigo aborda questões relacionadas a uma certa linhagem do teatro contemporâneo que, no texto, associamos ao conceito de "teatro energético" (Lyotard). Ao substituir a representação de conflitos pelos fluxos de intensidades, produções cênicas conectadas a essa vertente mobilizam uma cena que escapa ao esquema representacional de produção de sentido, dominante no nosso ambiente sociocultural, enquanto mecanismo de controle e poder. Nesse sentido, tudo aquilo que na cena da representação tende a domesticar a materialidade cênica em benefício de uma ideia de totalidade passa a dar lugar a um campo de tensão que põe em circulação fluxos de intensidade e cargas afetivas, transformando de forma radical a economia política do texto, orientada pelos signos, em uma economia libidinal, desencadeada pelas pulsões. $\mathrm{O}$ artigo traça, ademais, alguns apontamentos relacionados às formas de temporalidade, ética e política manifestadas no âmbito dessa vertente da cena contemporânea que, em sua variação contínua de velocidades e afetos, se afirma por meio da diferença em detrimento da identidade.
\end{abstract}

Palavras-chave: teatro contemporâneo, intensidade, temporalidade, não-representação, política, ética.

\footnotetext{
Abstract

A theater of intensities: subtraction of the elements of power in the contemporary theatrical scene

Starting with some aspects connected to the minor theatre conception (associated by Deleuze to Carmelo Bene's scenic operation) and, also, to the notion of pre-tragic 
theatre (suggested by Castellucci), this article discusses issues concerning a trend in the contemporary theatrical scene which, in the text, we associate with the concept of "energetic theatre" (Lyotard). By replacing the representation of conflicts with flows of intensity, scenic productions connected to this aspect mobilize a scene that escapes the representational scheme of meaningful production, dominant in our socio-cultural environment, as a mechanism of control and power. In this sense, everything in the representation scene which tends to domesticate scenic materiality to the benefit of an idea of totality, gives way to a field of tension that puts in motion flows of intensity and emotional charges, radically transforming the text's political economy, guided by signs, into a libidinal economy, triggered by impulses. The article also presents some remarks related to manifested forms of temporality, ethics and politics in the context of this contemporary scene which, in its continuous variation of velocities and affections, is affirmed through difference rather than identity.

Keywords: contemporary theater, intensity, temporality, non-representation, politics, ethics.

\section{Resumé}

Un théâtre d'intensités: soustraction des éléments de pouvoir dans la scène théâtrale contemporaine

À partir de quelques aspects attachés à la conception de théâtre mineur (associée, par Deleuze, à la mise-en-scène de Carmelo Bene) et aussi à la notion de théâtre pré-tragique (proposée par R. Castellucci), l'article traite des questions relatives à une certaine lignée du théâtre contemporain que, dans le texte, nous associons au concept de " théâtre énergétique »(Lyotard). En remplaçant la représentation de conflits par les flux d'intensités, des productions scéniques connectées à cette perspective mobilisent une scène qui échappe au schéma représentationnel de la production de sens, dominante dans notre environnement socioculturel, en tant que mécanisme de contrôle et de pouvoir. En ce sens, tout ce qui dans la scène de la représentation tend à apprivoiser la matérialité de la scène au profit d'une idée de totalité donne lieu à un champ de tension qui met en circulation des flux d'intensité et de charges affectives, transformant de manière radicale l'économie politique du texte, orientée par les signes, en une économie libidinale, déchaînée par les pulsions. Cet article souligne également quelques aspects liés aux formes de temporalité, d'éthique et de politique qui se manifestent au sein de ce volet de la scène contemporaine qui, dans sa variation continue de vitesses et d'affections, s’affirme par la différence au détriment de l'identité.

Mots-clés: théâtre contemporain, intensité, temporalité, non-représentation, politique, éthique.

\section{Introdução}

Quanto mais alguém atinge essa forma de consciência de minoria, menos se sente só. Luz. Sozinho se é uma massa, 'a massa dos meus átomos (Deleuze, 2010: 64). 
Recordam-se que este é o modo pelo qual Epicuro circunscreve a morte: se ela estiver ali, eu não estou lá; enquanto eu estiver ali, ela não está lá (Lyotard, 1997: 158-159).

O teatro é uma instituição. Uma instituição “oficial” (Deleuze, 2010: 57) que atua como órgão de representação dos conflitos reconhecíveis, previstos e controlados. E à medida que os conflitos (contradições, oposições entre o indivíduo e a sociedade, entre a vida e a história) já estão institucionalizados, codificados e normalizados eles se tornam "produtos" que acabam por configurar um fator de imobilidade para a própria arte teatral. Isto porque o teatro mesmo sendo de vanguarda, mesmo quando se pretende "crítico"- permanece representativo de cada vez que se vale dos conflitos e contradições padronizados, tornando-se, não raro, um teatro "narcísico, historicista e moralizante" (Deleuze, 2010: 58). Ao levar em consideração essa situação da representação conflituosa "oficial" e a necessidade de sondar abordagens que escapem ao poder desse teatro institucionalizado, Deleuze (2010) se questiona a respeito de como operar o trabalho subterrâneo de uma variação livre de modo a mobilizar linhas de fuga que ultrapassem as malhas da escravidão da cena modelar em meio à qual tudo gira em torno do signo majoritário.

Pela perspectiva do filósofo francês, o fato majoritário pressupõe um “estado de poder ou de dominação" (Deleuze, 2010: 59) - e não o contrário em que a maioria dominante não corresponde a uma quantidade maior, mas, sim, a um padrão dominante em relação ao qual as demais quantidades serão consideradas menores. Esse sistema de poder majoritário se impõe por meio de uma engrenagem que visa elevar eventos e ocorrências ao patamar "maior"; nesse sentido, de um pensamento se estabelece uma doutrina, de um modo de vida se edifica uma cultura, de um acontecimento se determina a História. Do ponto de vista discursivo, essa magnificação consiste em fazer reconhecer o que deve ser reconhecido e admirar o que deve ser admirado - sob a chancela de "relevância cultural"-, tendo como referência a unidade de medida do sistema majoritário; na prática, contudo, esse tipo de "enxerto" frequentemente acaba por criar mecanismos que, circunscritos ao limiar representativo, levam, no mínimo, à normalização.

Por outro lado - e na contramão disso - há trabalhos críticos que operam com vista a promover um processo de “minoração", isto é, um processo de variação que visa impor um tratamento menor aos acontecimentos de modo a permitir liberar devires, vidas e pensamentos contra as invariantes típicas da arte maior (História, cultura e doutrinas). Essa crítica pela variação, segundo Deleuze (2010), pretende afirmar o devir minoritário de todo mundo, em detrimento do fato majoritário de Ninguém. Para tanto, demanda o cuidado permanente no sentido de evitar que uma tal minoria seja alçada à condição de maioria e, com isso, acabe por reconstituir um padrão - o que, na visão do 
filósofo, reconduziria a arte à demagogia. Daí a necessidade de fazer com que o processo de variação passe ininterruptamente por caminhos inesperados como meio de garantir que a própria variação não deixe de variar.

No caso do teatro, inclusive, Deleuze se pergunta se esse trabalho de variação contínua - cuja abrangência, seja por excesso ou por escassez, ultrapassa o limiar da representação - não constituiria uma função crítica eficaz para traçar uma figura da consciência minoritária capaz de tornar uma "potencialidade presente" (Ibidem: 60). Nesse caso específico, o teatro em vez de representar conflitos, passaria a mobilizar a percepção direta da própria ação cênica, de modo a potencializar um tipo de presença em variação constante, a presença sensível de coisas e gestos, a carga afetiva de cada um. Adentraríamos, por conseguinte, um espaço no qual a ideia se faz visível, a política se impõe erótica e a crítica se torna uma constituição.

Essa função antirrepresentativa da arte, suficientemente modesta, ainda que eficaz, encontra pontos de ressonância no pensamento de diversos outros autores. Gumbrecht (2010), por exemplo, partindo de uma abordagem bem diversa (mas não menos crítica à forma institucionalizada de lidar com o mundo que impera num ambiente social e cultural no qual a atribuição de sentido, e não a percepção sensorial, se torna um fator primordial), também, ressalta na experiência estética a potencialidade de resgate da dimensão espacial e corpórea de nossa existência. Para o autor, frente ao predomínio da visão cartesiana do mundo ao longo dos últimos séculos, o valor da experiência estética se impõe à medida que ela nos impede de perder por completo a sensação da dimensão física, material das nossas próprias vidas, ou seja, a sensação de estarmos-no-mundo.

Além disso, por meio da experiência estética - sustenta Gumbrecht (2010) - podemos explorar as coisas tangíveis do mundo a partir de sua própria coisidade, isto é, pré-conceitual e concretamente, de modo a lhes evidenciar a "aparência" como camada diferente de sentido que escapa ao controle (tabu) discursivo "construtivista”. Não por acaso, o autor observa - a partir do filósofo alemão Martin Seel - que a aparência das coisas produz de forma recorrente a consciência dos limites do próprio controle humano sobre as coisas. O que, de certa forma, revela o caráter estratégico que o esquema representacional de produção de sentido, dominante no nosso ambiente sociocultural, encerra enquanto mecanismo de controle e poder.

Diante desse arsenal teológico construído com o objetivo de estabelecer padrões de unidade e a partir deles identificar nos acontecimentos um significado primordial, um referente ulterior, ou, ainda, um sentido transcendental, uma vertente da cena teatral contemporânea atua no sentido de subverter tais esquemas de poder, declinando a reproduzir esse padrão de funcionamento da cena engendrado por meio do acúmulo incessante de discursos e representações. Em sua crítica constituinte, tal vertente denuncia as obstruções da 
realidade cênica resultantes de processos que tendem a domesticar a materialidade dos elementos da cena em benefício de uma ideia de totalidade, de modo a rebaixar a cena à condição de mero dispositivo de ressonância e reiteração.

Desta sorte, frente ao enfoque semiótico predominante no padrão de pensamento discursivo, sobrevém uma abordagem que podemos designar energética, pulsional, ou ainda, libidinal à medida que encara a realidade como um espaço atravessado por pulsões não redutíveis a uma finalidade previamente estabelecida. Mobilizando um tipo de pensamento-corpo que acolhe os acontecimentos por uma via que não a da intervenção dominadora - e sem recusar a sua posição de resistência diante dos processos de controle do tempo -, tal enfoque se afasta radicalmente das abordagens de caráter representacional.

Caberia, então, perscrutar as implicações de uma abordagem dessa natureza (em que forma e sujeito aparecem sempre subordinados à variação intensiva de velocidades e afetos) no âmbito do próprio teatro. Para Lyotard, um teatro que operasse a partir das suas pulsões e intensidades produziria eventos efetivamente descontínuos. Ao mesmo tempo, no ensaio $\mathrm{O}$ dente, a palma em que discorre sobre um "teatro de energias" que escapa ao modelo representativo no qual cada signo está sempre remetendo a uma outra realidade, o próprio Lyotard, se pergunta: Isso é possível? Como?

São questões desafiantes e para as quais não existe solução fácil. Mas o tamanho e a complexidade da empreitada não devem gerar intimidação; há de se encarar a necessidade de traçar alguns "esboços", rabiscar (e, se necessário, rasurar) linhas de um pensamento "menor", como forma de tangenciar possíveis respostas às questões lançadas pelo filósofo.

São questões desafiantes e para as quais não existe solução fácil. Mas o tamanho e a complexidade da empreitada não devem gerar intimidação; há de se encarar a necessidade de traçar alguns "esboços”, rabiscar (e, se necessário, rasurar) linhas de um pensamento "menor", como forma de tangenciar possíveis respostas às questões lançadas pelo filósofo.

Como forma não apenas de rever e ampliar aspectos de uma investigação por nós desenvolvida no âmbito do doutoramento, mas também como meio de operar uma autorreflexão sobre o nosso próprio percurso no campo do teatro $^{1}$, este artigo aborda questões relacionadas com esta linhagem do teatro contemporâneo que, ao substituir a representação de conflitos pelos fluxos de intensidades, faz mobilizar uma cena que escapa a todas as formas de poder que asseguram a possibilidade de "agarrar" a matéria sensível por meio das formas, do conhecimento, das sínteses e dos conceitos. Para tanto, o estudo promove, como estratégia metodológica, o resgate de um pequeno trecho de nossa tese de Doutoramento "Teatro menos teatro" - defendida no âmbito

1 Não numa perspectiva autobiográfica ou “autoral”, mas antes a partir de um pensamento lateral que se perfaz no jogo com o "outro".

2 Cf. Belloni (2011). 
do Departamento de Artes Cênicas da Universidade de São Paulo - e, a partir dele, opera uma série de variações no sentido de expandir aspectos do referido texto, de modo a explicitar o que nele existia apenas virtual e potencialmente, a saber, os sentidos ético e político de um teatro que se configura por meio de uma espécie de espacialização de intensidades.

Adotando essa perspectiva, o artigo toma como ponto de partida alguns aspectos ligados à noção de teatro pré-trágico (sugerida por R. Castellucci), e, também, à concepção de teatro menor (associada, por Deleuze, à operação cênica de Carmelo Bene) para, logo em seguida - e tendo como base estudos de outros pesquisadores do teatro e da arte em geral -, traçar alguns apontamentos relacionados às formas de temporalidade, ética e política manifestas no âmbito dessa corrente "energética” da cena contemporânea.

\section{0 teatro pré-trágico e o teatro menor}

$\mathrm{Na}$ introdução do seu texto "O peregrino da matéria", Romeo Castellucci afirma que "todo trabalho que assume uma qualidade orgânica vai ao encontro de sua própria animalidade. Cada trabalho pode ser resumido de uma forma animal. É esta a maneira aristotélica de considerar o teatro" (Castellucci, 2007: 181). A imagem do animal, neste sentido, torna-se idealmente representativa de uma certa organicidade para boa parte do teatro. Contudo, Castellucci reclama a necessidade de resgatar a materialidade daquilo que, a partir da Tragédia Ática, passou a existir apenas na forma de pura fantasmagoria. Nesse sentido, recoloca, de forma literal, o animal em cena, num gesto que, segundo o próprio artista italiano, expõe a necessidade de ir ao encontro da raiz teológica e crítica de um teatro pré-trágico cuja natureza seria infantil, sendo a "in-fância” a condição de quem está "fora da linguagem”.

Daí a importância de um teatro elementar que, comunicando o menos possível, promova a peregrinação da matéria. Um teatro em que a dialética não tem lugar, à medida que, justapostos, mesmo os elementos extremos do início e do fim passam a penetrar violentamente um no outro, escapando a qualquer forma de estruturação dialética. "Só uma contraposição do tipo químico pode desencadear reações que fogem ao controle. Estas reações podem desencadear o acaso; a casualidade" (Ibidem, 182).

Outro aspecto para o qual Castellucci nos chama a atenção diz respeito ao fato de que, além de estar vinculado a uma concepção materialista das coisas, o pré-trágico associa-se diretamente à potência do gênero feminino. De acordo com esse viés, a arte do teatro pré-trágico, ao sair da esfera linguística, adquire um vínculo privilegiado com a figura materna, associada ao corpo gerador e ao corpo recomposto pela sepultura. 
De certa maneira, essa predisposição para se afastar do modelo trágico se deve ao fato de que a tragédia, na sua concepção clássica - conforme observa Vernant (2005) - , está relacionada com a obra de poetas que, de forma deliberada, transpuseram o mito visando a inserir nele um sentido humano, por meio de um tipo de pensamento prioritariamente discursivo ou dianoético, e não intuitivo/imediato ou noético ${ }^{3}$. A consciência trágica, dessa maneira, instaura-se a partir do momento em que o mito passa a ser considerado a partir do ponto de vista dos cidadãos (homens maduros e com total controle de suas faculdades mentais), passando a tragédia à condição de instituição social que a cidade estabelece junto a suas instituições políticas legais.

Outro ponto que cabe ser ressaltado em relação à tragédia diz respeito ao seu papel determinante no processo de conscientização do homem grego, na virada dos séculos V e IV a.C., quanto aos dados representacionais - ficcionais - manifestos no empreendimento trágico, à medida que por meio de seu ofício, o poeta grego se descobre como puro imitador, criador de fábulas e simulacros cujas aparências enganosas constituíam um mundo paralelo ao "real", o da pura ficção.

(...) Visto que a tragédia coloca em cena uma ficção, os acontecimentos dolorosos, aterradores que ela mostra na cena produzem um outro efeito, como se fossem reais. (...) Como seu modo de existência é imaginário, eles são postos à distância, ao mesmo tempo que representados. No público, desvinculado deles, eles "purificam" os sentimentos de temor e de piedade que produzem na vida cotidiana. Se os purificam é porque, em vez de fazê-lo simplesmente experimentá-los, trazem-lhe, através da organização dramática (...), uma inteligibilidade que o vivido não comporta. Arrancados da opacidade do particular e do acidental pela lógica de um roteiro que depura simplificando, condensando, sistematizando, os sofrimentos humanos, comumente deplorados ou sofridos, tornam-se, no espelho da ficção trágica, objetos de uma compreensão. Em relação às personagens e aos acontecimentos singulares, ligados ao quadro histórico e social que é o seu, adquirem um alcance e um significado muito mais amplo (Vernant, 2005: 218-219).

$3 \mathrm{O}$ nous, enquanto pensamento não-discursivo e não-propositivo, pode ser relacionado ao pensamento que mobiliza o "acesso imediato ao real" (MARCONDES, D. Noûs vs. Lógos. En: O que nos faz pensar. Rio de Janeiro, PUC-Rio, 1989, $\mathrm{N}^{\circ} 1$ : 13); ou ainda, conforme sugere Heidegger, o nous responde a um modo concreto de lidar com o mundo enquanto energeia. Já a dianoia, ou "razão prática”, consiste na faculdade de pensar ou raciocinar, exercendo o seu ofício com a deliberação e com a escolha dos meios (os particulares) que levam ao fim (o universal), aqueles e estes sendo considerados dialeticamente. 
Por esse viés, pode-se afirmar que a tragédia é a cidade que se coloca em cena como ficção, ou seja, a cidade (e por extensão, o governo, a autoridade, o poder - kratos - e suas instituições) se fazendo teatro diante dos cidadãos. Nesse sentido - e em última instância -, afastar-se do modelo trágico em direção ao que seria o pré-trágico consiste, dentre outras coisas, em afastar-se de questões relacionadas com a esfera do poder, o que implica suprimir ou minimizar os elementos de/do poder presentes não só no campo da ficcionalidade, como no da própria escritura trágica (o discursivo e o legível perdem espaço para o figural - restituindo a um agente particular sua singular opacidade -, assim como os fluxos e intensidades passam a substituir a estrutura fabular).

Deve-se ressaltar, contudo, que o gesto de eliminar ou minimizar os elementos de poder não implica a renúncia ao plano político. Passa-se apenas a reconsiderá-lo a partir de outro lugar, por uma nova perspectiva. Nesse sentido, talvez seja possível dizer com Cornago (2008) que o plano político passa a ser revisado desde um momento anterior, contudo não na acepção temporal do termo "anterior", mas sim no sentido de "coexistência permanente - do mesmo modo como Agamben propõe o conceito de 'infância' referido à história: a representação nascendo do encontro, ou a história surgindo de um momento prévio no qual ainda não se tem consciência dela” (Cornago, 2008: 26).

Que o homem não seja sempre já falante, que ele seja também in-fante. Isto é o que Agamben (2008) concebe como experiência. Logo, um teatro pré-trágico, por sua natureza infantil, pode ser associado não só a um teatro da experiência e a uma estética da presença, mas também a uma política de Eros. No caso de Castellucci, essa hipótese parece ainda mais provável à medida que este afirma que "se há uma polêmica em relação à tragédia ela está, sem dúvida, ligada ao papel do autor, ao movimento da escritura e, portanto, a esta incrível pretensão de verticalidade sexuada" (Castellucci, 2007: 181-182).

Estes aspectos sugeridos pela noção de um teatro pré-trágico, assim como a dimensão gestual que eles acabam adquirindo no âmbito de certos trabalhos da Societas Raffaello Sanzio ${ }^{4}$, remetem diretamente a certos traços do teatro de Carmelo Bene, apontados por Gilles Deleuze (2010) no ensaio Um manifesto de menos, no qual o filósofo francês se volta para o teatro menor de Bene, um dos artistas pioneiros do teatro performático italiano. No texto, como se sabe, Deleuze (2000) chama a atenção para o que reconhece no teatro de Bene como uma espécie de perturbadora subtração, amputação, neutralização dos

\footnotetext{
4 Sobre a montagem de Giulio Cesare (1997), por exemplo, DIB (2009) sustenta que "Há um homem laringotomizado, sobre o pódio de honra, reinventando a voz, a retórica de seu discurso, enquanto Bruto inala gás, abre a garganta, se engasga, inala e sufoca tornando o seu discurso um ato impossível e falbo. (...) São homens-estátua, imóveis, vestidos com panos que resumem o poder e a política, mas que estão esvaziados de uma e de outra (...)" (DIB, 2009, pg. 102). Pudemos presenciar parte desse conjunto em uma versão sintetizada do espetáculo, destinada a espaços não-convencionais. Sob o título Júlio Cesar - Peças soltas, o espetáculo foi apresentado no Mosteiro de São Bento da Vitório, Porto, entre os dias 30 e 31 de Março de 2017.
} 
elementos que constituem ou representam um sistema de poder, quais sejam, os elementos que garantem a coerência tanto do sujeito e do tema, quanto da representação no palco, ou seja, do poder relacionado ao que é representado e do poder do próprio teatro enquanto sistema representativo, uma vez que uma instância está incrustada na outra.

Nesse sentido, ao amputar os elementos de poder, Bene altera não apenas a "matéria" teatral, aniquilando elementos do contexto ficcional associados às estruturas e instituições de poder - como, por exemplo, no caso de sua montagem de Romeu e Julieta em que suprimiu todo o poderio relacionado com a família, à realeza (Estado) e seus respectivos correlatos -, mas também a própria forma de teatro, que deixa de ser uma representação, ao mesmo tempo em que o ator deixa de ser um ator, passando o espaço cênico a configurar um campo aberto para a manifestação de diferentes formas e matérias teatrais. Isso porque, de acordo com o filósofo francês, o verdadeiro poder do teatro (Texto, Diálogo, Ator, Encenador, Estrutura) acaba não sendo discernível daquilo que configura a própria representação do poder no teatro (Reis, Príncipes, Senhores, Sistema), por mais crítica que ela se queira ou possa, de fato, ser. Não por acaso, na cena de Bene, o homem de teatro passa da condição de autor, encenador e/ou ator à de operador da cena; entendendo-se, aqui, por operação, o movimento de subtração dos elementos do poder que no teatro asseguram a coerência da forma e do sujeito (no sentido de "tema" e de "eu").

Percebe-se assim que a crítica operada pelo teatro de Bene é consequência de uma constituição e não de uma representação. Trata-se de um teatro constituinte no qual os conflitos - entre os elementos do plano cênico e não do ficcional, cabe destacar - nada mais são que suportes para a variação. Nada de forma, apenas velocidades; nada de sujeito, apenas afetos.

\section{Subtração e iconoclastia}

Para Deleuze (2000), Bene pertence a um movimento não representacional que, subvertendo de forma radical a lógica do teatro representacional, poderia ser associado a criadores como Artaud, Bob Wilson, Grotowski, Living Theater e outros. Contudo, de acordo com o filósofo - para quem, aliás, as alianças são mais importantes que as filiações -, o teatro de Bene impõe sua diferença à medida que promove a subtração dos elementos estáveis de poder, por meio de uma operação que mobiliza forças radicalmente não representativas, rompendo, além disso, com o "psicodrama" do teatro vivido, o formalismo do teatro esteta e o ascetismo do teatro místico. Ao investir na operação subtrativa (e com isso acenar para um tipo de abordagem da cena que não passa pela representação de conflitos, nem tampouco pela crítica à sociedade ou aos países), Bene acaba por agenciar, segundo Deleuze, um teatro "menor", em oposição ao teatro "Maior", passando a se dedicar menos às questões referentes ao 
começo e ao fim das coisas, de modo a sondar aspectos relacionados com que se encontre "no meio", "entre", enquanto instância extemporânea - menos da mediania que do excesso - em que diferentes tempos se comunicam; e em que devires, vidas, pensamentos, graças ou desgraças, substâncias próprias a uma arte "menor", superam História, cultura, doutrinas e dogmas, típicas referências da arte "Maior".

Essa subtração, por esse viés, não implica uma operação negativa à medida que ela mobiliza e desencadeia também processos positivos. Isso porque o próprio movimento de subtração acaba por ser recoberto por um outro movimento que faz passar tudo por uma espécie de variação contínua, ensejando a irrupção e proliferação de algo inesperado, sub-representativo; emergência abrupta de uma variação criadora que, agindo como um raio, anuncia uma coisa não previamente projetada ou imaginada. Não por acaso, Deleuze (2010) considera o teatro de Bene um teatro-experimentação que opera por meio de subtrações com o intuito nada desprezável de fazer "ver o que acontece".

Eliminam-se História e estrutura, enquanto indicações, respectivamente, diacrônica e sincrônica do Poder que se sustentam por meio da estabilização dos elementos. Amputa-se o texto, à medida que este submete a fala à linguagem, apelando à invariância e à homogeneidade. Retira-se o diálogo porque este também determina a adição de elementos de poder à fala (linguistas tentam definir e codificar os "universais do diálogo"). Mas, em meio a toda essa operação subtrativa (menos texto, menos diálogo, menos conflito, menos ator, menos diretor, menos estrutura), o que permaneceria? - pergunta Deleuze (Ibidem: 42) de forma aporética, para em seguida afirmar: Tudo permanece, mas sob nova luz, novos sons e novos gestos. Nenhum tema, sujeito ou forma, apenas uma geometria de intensidades, velocidades e afetos que submete formas qualificadas à deformidade do movimento ou da qualidade.

Deve-se afirmar, contudo, que a ideia da subtração, aqui, não implica banimento, extermínio, desterro. Teatro menos texto, não implica um teatro sem texto. A ideia de minorizar não deve ser confundida com a ideia de negar. Como ressalta Deleuze (2000), não se trata de uma perspectiva única e exclusivamente antiteatral, no sentido da negação do teatro - nos termos do que preconizava um Marinetti, por exemplo, com sua "teatralidade sem teatro". O teatro de Carmelo Bene não comunga das fórmulas das vanguardas. Seu esforço anti-representacional não é operado "fora do espetáculo", de modo que, sua negação do teatro se dá no âmbito do próprio teatro.

Nesse ponto, a radicalidade da subtração operada por Bene encontra franca correspondência com a não menos radical noção de iconoclastia operada por Castellucci, uma vez que ambas as operações encerram uma força opositiva que escapa à tradição iconoclasta das vanguardas que negavam e destruíam tudo o que não apontasse para a bandeira da frente que as orientava em sua marcha revolucionária rumo ao novo. No caso de Bene e Castellucci, ao 
contrário desse caráter "dessacralizante e irônico", impõe-se um gesto "reconsagrador e verdadeiro" (Castellucci, 2009: 125) que, a um só tempo, promove uma espécie de iconoclastia do próprio conceito de iconoclastia, possibilitando viajar na - irremediavelmente distante - "concha vazia" da forma clássica teatral.

(...) O teatro, e qualquer forma de arte que não se confronte com a própria possibilidade, factual, de não existir, não me interessa (...) A guerra iconoclasta é em primeiro lugar, contra a inconcebível pretensão de representar alguma coisa e depois, contra o próprio conceito de iconoclastia, em seu intenso desejo de pulverizar as figuras. A iconoclastia é, em última instância, para remover a si mesma e inclusive ao sim. A figura sobrevive à fúria pantoclasta, por ela mesma celebrada só entregando-se às chamas, como o bronze que demonstra o seu não. A figura envolta pelo fogo é a figura que nega a iconografia, e nega, enfim, a iconoclastia na qual foi duplamente gerada, isto é, "regenerada". Como na sintaxe latina uma dupla negação equivale a uma condição neutra, assim o apocalipse da figura já está feito é agora o neutro, um neutro que permanece incoercível ao sistema binário da tradição (Castellucci apud Dib, 2009: 135-137).

Conforme sustenta Colwell (1997), para Nietzsche e Foulcault, o poder - a vontade de poder em todas as esferas de sua manifestação - está relacionacionado àquilo que pretende fixar o evento numa atualização determinada e estável. Por este viés, pode-se inferir que tanto a subtração de Bene quanto a "iconoclastia da iconoclastia" de Castellucci acabam por subverter os traços do poder, uma vez que, a partir dos agenciamentos perpetrados por cada um deles, tem-se o testemunho claro do que podemos reconhecer como sendo a operação de uma sub-tração em que a repetição se liberta da repetição para repetir a sua própria ausência. Indo de encontro a toda uma tradição presa à lógica representacional, essa variante de teatralidade, radicalmente, antiteatral substitui a emissão de ideias e intencionalidades pelos fluxos de intensidades, de modo a mobilizar uma cena que escapa a toda forma de determinação do ser enquanto presença plena: “O presente só se dá como tal, só aparece a si, só se apresenta, só abre a cena do tempo ou o tempo da cena acolhendo a sua própria diferença intestina, na dobra interna da sua repetição originária (...)" (Derrida, 1995: 173).

\section{0 tempo real}

Tanto o teatro de Bene, quanto o de Castellucci, superando o niilismo típico 
das modalidades representativas e suas estruturas hierárquicas de poder, aliam-se àquela corrente da cena contemporânea na qual, como afirma Sílvia Fernandes, "o que passa a determinar o trabalho de construção da cena é o princípio da literalidade, responsável por colocar em jogo, ou em confronto, a materialidade dos elementos que constituem a realidade específica do teatro" (Fernandes, 2009: 15). Para Fernandes, a desativação da função simbólica de um objeto por meio da exposição literal do mesmo, nos termos do que ocorre, por exemplo, em teatros da literalidade como os de Tadeusz Kantor, Ian lauwers, Gilles Maheu, Heiner Goebbels e do próprio Castellucci, acaba por gerar situações de linguagem carregadas pela manifestação extremada da matéria teatral, em que o sensível se torna significante.

Diante desse quadro em que a literalidade parece, de fato, se impor, torna-se relevante a sondagem das formas de modulação temporal nele manifestadas. Discorrendo sobre essa mesma linhagem performativa da cena contemporânea, Renato Cohen observa que, nela, tende-se a privilegiar "sincronia e geografia de associações - em detrimento do recurso temporalizador" (Cohen, 2001: 108). Todavia, ainda que não haja o arco temporal ligado ao desenvolvimento de uma ação própria a um determinado cosmos narrativo de ficção, surgem, nesse contexto, possibilidades temporais diferenciadas, a começar pela própria recuperação da "ideia de 'tempo real' em contraposição ao tempo simbólico do espetáculo”(Cohen, 2003: 120).

Essa incorporação da temporalidade "real" pode ser, inclusive, observada em um espetáculo como Ueinzz - Viagem a Babel (1997), dirigido pelo próprio Renato Cohen ${ }^{6}$, juntamente com os integrantes da Cia. Ueinzz, formada por usuários dos Serviços de Saúde Mental do Hospital Dia - a Casa, em São Paulo. Considerado por Fernandes (2009) um dos exemplos mais contundentes da experiência cênica com corpos desviantes, a montagem promovia a exposição de figuras no limiar da loucura, cuja presença em cena, de natureza extra-cênica, logo se revelava mais como sintoma que como símbolo. Não por acaso, a pesquisadora observa que nessa experiência possivelmente acontecesse "o que Jean-François Lyotard chama de 'teatro energético' para referir-se a um teatro que não procura a significação, mas as forças, as intensidades e as pulsões de presença” (Fernandes, 2009: 45).

Referindo-se a um comentário feito por um espectador a respeito do trabalho, Pelbart (2000) observa que, no espetáculo, tudo acontece por um triz, e esse por um triz jamais é ocultado; de modo que o espectador nunca tem a certeza e a segurança de que um determinado gesto (ou fala) terá, de fato, um desfecho, à medida que ele pode ser interrompido por uma contingência qualquer, num contexto em que cada minuto passa a ser vivido como uma espécie de "milagre". Tal índice de indeterminação é corroborado por Cohen, num 
texto em que ele relata que, por vezes, os atores abandonavam a cena antes mesmo de completarem suas falas, de modo que acabavam por compor o que Cohen chama de "estridente partitura de erros, de achados, de reinvenção de texto" (Cohen, 2003, p.120).

O recurso ao "tempo real” é, também, apontado por Hans-Thies Lehmann (2007) como um fenômeno estético-teatral recorrente da cena "pós-dramática”, estando associado a um padrão de temporalidade que promove uma imagem direta do tempo em estado puro, como na "imagem-tempo" deleuziana - constituída por cristais de tempo; de modo que o tempo do próprio procedimento teatral passa a ser processado, elaborado e refletido do ponto de vista artístico, desencadeando um tipo de experiência temporal diferente daquela, habitualmente, vivenciada, seja no âmbito do teatro narrativo, seja na instância do nosso próprio cotidiano. Ao conjugar fatores rítmicos e visuais à dramaturgia cênica, o teatro assume os contornos de um objeto cinético, convocando um tipo de percepção teatral que, tal como na dinâmica do olhar instaurada diante de uma obra plástica, mobiliza processos, combinações e ritmos a partir dos dados lançados em cena, contudo, sempre sob direção própria. Consequentemente, tem-se uma oscilação do foco de percepção entre o acompanhamento cênico e o "olhar-temporalizante". De acordo com Lehmann, o teatro passa, então, a fazer parte da problemática da temporalidade dos fatores visuais.

A instalação desse "objeto cinético" e a consequente ativação na recepção teatral desse modo de disposição temporal, cabe observar, já há muito vinha sendo explorada no campo das artes plásticas. Conforme nos lembra Rosalind Krauss, a condição temporal própria às esculturas de Duchamp e Brancusi, por exemplo, é a do tempo real, ou tempo experimentado (Cf. KRAUSS, 2007: 129). Tal variedade temporal, contudo, ao contrário de compor apenas objetos tautológicos que são sempre e exatamente como são - o que implicaria, conforme Didi-Huberman, a eliminação de toda temporalidade ${ }^{7}-$, acaba por promover modos de "duração", ou melhor, de experimentação do tempo que, talvez, possam ser associados àquilo que, segundo Lyotard (1997), designa o "tempo de Deus" e o "tempo do átomo": extremidades da ordem do tempo entre as quais “a temporalidade pode pensar" (Lyotard, 1997: 162) e que, observadas pelo campo da lógica, passam a ser, a um só tempo, como a tautologia ( $p$ é $p$ ) e a contradição ( $p$ é não $p$ ), uma vez que, a despeito de serem proposições, escapam a qualquer tarefa de síntese e/ou cálculo de verdade.

7 “E esses objetos só ‘são' tão exatamente porque são estáveis”, conforme observação feita por DidiHuberman a respeito da disposição de forjar objetos tautológicos por parte de alguns artistas plásticos ligados ao minimalismo (Donald Judd, Frank Stella e Robert Morris), numa tentativa de eliminar toda a temporalidade dos mesmos (Cf. DIDI-HUBERMAN, 1998: 56). 
Talvez, seja possível relacionar essas duas modalidades de tempo com aquilo que Gumbrecht (2010) chama de "temporalidade extrema" para se referir a uma ordem temporal associada a um tipo de presença cujos efeitos já estão, desde o seu nascimento, permeados de ausência. Nas condições de "temporalidade extrema", a presença - pelo menos a presença nas condições contemporâneas - não acontece sem apagar aquela outra presença que a representação gostaria de designar (a partir da identificação dos fundamentos, da origem ou do tema). Isso porque, nessas condições, o que se evidencia é a própria substância do significante, e não o sentido a ele relacionado. Tal presença, ademais, nunca passa a uma situação permanente, estável, de modo que jamais se deixa agarrar, conquistar. Já evanescente em seu nascimento, ela "é a chegada que apaga a si mesma e devolve a si mesma” (Nancy apud Gumbrecht, 2010: 82).

Ao revelar a ausência de qualquer tipo de estabilidade/positividade da composição, essas variantes de temporalidade (sugeridas por Lyotard e Gumbrecht), possivelmente, determinam um tipo de experiência temporal próxima daquela mobilizada pelas geometrias de intensidades, velocidades e afetos apontadas por Deleuze (2010) em seu ensaio sobre Carmelo Bene, num trecho que faz referência à variação contínua de gestos e enunciados operada em cena pelo artista italiano. Pela perspectiva do filósofo, o teatro de Bene agencia uma linha de transformação que, de forma ininterrupta, faz nascer e proliferar o inesperado através da distribuição de velocidades e intensidades entre diferentes pontos de um móvel e de um sujeito, gerando assim uma série contínua de metamorfoses e variações.

Outra possível conexão pode ser estabelecida entre tais temporalidades e aquela acionada por alguns dos protótipos da escultura "teatral" cinética do início do século XX, diretamente vinculados, por Rosalind Krauss, ao conceito de teatralidade. Conforme a crítica e historiadora americana, o Acessório de $l u z$, de Moholy-Nagy e o cenário criado por Picabia para Relâche - produzido pelos Ballets Suédois - encerravam aspectos expressamente teatrais à medida que, para além de terem sido destinados ao palco e, consequentemente, ao desenrolar de acontecimentos temporais, ambos os trabalhos revelavam que os seus feitores "consideravam a luz como energia, não como uma massa estática, e, portanto, como um veículo em si mesmo temporal” (Krauss; 2007: 247); desinvestindo, por conseguinte, qualquer tipo de abordagem puramente tautológica.

Esse processo de variação contínua, se não elimina de vez os mecanismos que sustentam a lógica da representação, acaba por fragilizá-los, uma vez que interfere no próprio modo de funcionamento da máquina representacional que, conforme observa Cornago (2006), passa à condição de mecanismo avariado. Essa disfuncionalidade residual peculiar à cena artística que tenta alcançar o momento prévio à representação, ademais, é extensiva ao modelo 
representacional da realidade como um todo - e o entendimento, dele decorrente, da realidade como signo dialético de uma outra realidade, de ordem essencial, situada num mais além. Por esse viés, e em última instância, antes de ser um fenômeno isolado, o processo relativo à decomposição do aparato representacional reflete um fenômeno histórico-cultural mais geral ${ }^{8}$.

\section{Potencialidade amorosa}

Discorrendo sobre a concepção de "ética fundamental" de Emmanuel Lévinas, Cornago (2008) nos lembra que, para o filósofo francês, a situação ética fundamental finda quando começa a relação "social”, ou seja, antecede o campo da moral e da lei. Nesse sentido, a situação ética fundamental - mobilizada, de modo geral, pela cena artística que tenta alcançar o momento prévio à representação - é reflexiva de um encontro físico imediato, um cara a cara, construído com base em rostos que ainda não têm nome, à medida que antecede o fenômeno social, e com ele a história, o político. Em meio a essa ruptura radical da representação, o valor da palavra "implicação" se impõe como crítica desarmada, agenciando uma cena que demanda um jogo pautado menos pelo distanciamento que pela proximidade.

Talvez seja inclusive nesse ponto, em que já não há mais nada a representar, que o teatro ou a arte possa sobrevir com uma possível implicação política. No ponto em que, em vez de adicionar uma representação - uma a mais - ao já saturado arsenal de representações que faz engrenar as máquinas da história e da sociedade, opera-se no sentido de subtrair - uma a menos - a própria representação; isto feito não apenas como modo de negação do mecanismo de poder que engendra toda e qualquer representação - haja vista que "não há signo nem pensamento do signo que não sejam de poder e com poder" (Lyotard apud Cornago, 2010: 372), mas também como gesto de exposição que refuta o pressuposto de que os elementos cênicos devem estar ancorados em base representacional.

Por esse viés, conforme observa Cornago (2010), já não se faz necessário que os elementos cênicos se justifiquem em função da representação; a representação é que, pelo contrário, deve ser justificada na medida em que se faça traduzir naquilo que, simplesmente, acontece. Isso porque, nesse contexto, a cena espacializa um jogo performativo de tensões entre figuras de superfície que circulam no plano espacial, e as cargas de profundidade e sentido apontadas posteriormente. Sim, porque não se trata de rechaçar possíveis sentidos de um trabalho, mas, diferentemente disso, de afirmar uma ação de resistência contra sentidos previamente construídos. Um ato de libertação dos acontecimentos e de constituição de um espaço de autonomia da arte . 
Talvez seja possível reconhecer alguns aspectos desse caráter disfuncional do aparato representativo a partir do modelo de escritura cênica operado no âmbito de algumas produções teatrais contemporâneas. Em seu ensaio Teatro y poder: estrategias de representación en la escena contemporánea Cornago (2006) chama a atenção para o modo como, em certas produções de Kantor e Bartís, circulam figuras que parecem tentar em vão acionar a engrenagem de uma representação que já não funciona. Ou quando funciona, atua de modo muito precário, como se a máquina de grafar o texto espetacular (por meio dos corpos, movimentos, palavras e sons) operasse em cena de modo similar ao de um mecanismo que, em vez de imprimir seus sinais em um suporte passível de inscrição (tábula, papel), apenas esboçasse sua escrita numa superfície fluida e movente (água, areia); configurando, por conseguinte, uma escritura que não deixa rastros; apenas acontece até o ponto de existir tão somente nesse estar-acontecendo; isso é, no próprio ato de acontecer. Este tipo de escritura, à medida que se constitui e se oblitera no mesmo ato, parece se sustentar, sobretudo, no instante de sua ocorrência, desencadeando um processo material e efêmero, destituído de resultados textuais projetáveis. Assim sendo, tal processo espacializa um não-regime de dispêndio e gozo que, pela perspectiva de Cornago (2006), configura um ato (cênico) de resistência contra sentidos previamente construídos; conferindo, em última instância, um ato de libertação do acontecimento.

No âmbito desse tipo de apresentação negativa, a arte testemunha no sensível que algo o excede, o extrapassa, violenta. Talvez seja exatamente a partir desse ponto que o teatro, escapando a toda e qualquer forma de intervenção dominadora/controladora, possa traçar - ainda que não de forma exclusiva possíveis linhas de fuga que se constituam políticas. Sobre esse aspecto, cabe lembrar que, pela perspectiva do Gilles Deleuze, a função política específica da arte teatral surgirá quando o teatro, afastando-se da representação e indo ao encontro da sua potencialidade amorosa, apresentar e constituir uma consciência de minoria, enquanto devir-universal; "seguindo linhas de transformação que saltam para fora do teatro e assumem uma outra forma, ou se reconvertem em teatro para um novo salto (Deleuze, 2010: 64). Por esse viés, a transformação decisiva da consciência se alcança quando ela abandona as soluções e interpretações, passando a conquistar seus próprios sons, gestos e luz; ou ainda, poderíamos acrescentar a partir de Lyotard (1997b), quando ela, desassistida de qualquer poder, se deixa atravessar por um acontecimento cujo toque não deixa qualquer sinal. Um toque sem inscrição reflexivo de uma escrita livre de qualquer suporte, significação, conceito e/ou forma (pré-inscritos) ${ }^{10}$. Daí,

10 Discorrendo sobre um modelo de escritura que se estabelece por meio de uma procura constante daquilo que nunca se inscreve - e que é, a um só tempo, acontecimento e aquilo ao qual acontece algo -, Lyotard (1997b: 159-160) propõe, a certa altura, falsear o valor do prefixo e da palavra "escrita", de modo a evocar o significado da raiz scri (fora de), como forma de cogitar uma escrita livre de qualquer suporte, conceito e/ou forma pré-inscrita. 
provavelmente, o fato de Lyotard evocar os fluxos libidinais e os deslocamentos afetivos ao se referir à sua concepção de teatro energético. Um teatro de intensidades no qual tudo aquilo que na cena da representação normalmente é bloqueado, ordenado, represado, direcionado - em nome de um mundo ficcional, de uma mensagem moral ou de um sentido ulterior - passa a dar lugar a um campo de tensão que põe em circulação fluxos de intensidade e cargas afetivas, transformando de forma radical a economia política do texto, orientada pelos signos; em uma economia libidinal, desencadeada pelas pulsões.

\section{Referências bibliográficas}

AGAMBEN, G (2008), Infância e História: Destruição da Experiência e Origem da História, Belo Horizonte, Ed. UFMG.

AGAMBEN, G (2009) O que é contemporâneo? E outros ensaios. Chapecó, SC: Argos.

BELLONI, A (2011), "Teatro menos teatro", Tese de Doutoramento, São Paulo: ECA/USP.

CASTELLUCCI, R (2007), O peregrino da matéria, In: Sala Preta, São Paulo: ECA/USP, n.7, 181-187.

CHIESA, Lorenzo (2009), "A Theatre of Subtractive Extinction: Bene Without Deleuze”, Laura Cull (org.), Deleuze and Performance, Edinburg: Edinburg University Press, 71-88.

COHEN, R (2001), "Cartografia da cena contemporânea: matrizes teóricas e interculturalidade”, In: Sala Preta, São Paulo: ECA/USP, n.1, 105-112.

COHEN, R (2003), "Rito, Tecnologia e Novas Mediações na Cena Contemporânea Brasileira", In: Sala Preta, São Paulo: ECA/USP, n.3, 2003, 117-124.

CONNOR, S (2001), Mortification. En: Ahmed S., Stacey J. (ed.), Thinking through the skin, London, Routledge.

CORNAGO, Óscar (2008), Teatralidade e ética. In Saadi F. e Garcia S. (org) Próximo ato: Questões da Teatralidade Contemporânea, São Paulo: Itaú Cultural, 20-31

CORNAGO, Óscar (2010), Teátrica pagã: diálogos de Jean-François Lyotard com a cena, Sala Preta, v.9, 371-381.

CORNAGO, Óscar (2006), Teatro y poder: estrategias de representación en la escena contemporánea, Iberoamericana, v.6, n.21.

COWELL, C (1997), "Deleuze and Foucault: Series, Event, Genealogy", In: Theory \& Event. Baltimore: The Johns Hopkins University Press, Volume 1, Issue 2, 71-90.

CULL, Laura. (2013) Theatres of Immanence: Deleuze and the ethics of performance, England: Palgrave Macmillan.

DELEUZE, G. (2000), “One less manifesto”, In: MURRAY, Thimothy. Mimesis, masochism \& mime, The politics of theatricality in contemporary French thought, Ann Arbor: The University of Michigan Press.

DELEUZE, G (2010), Sobre o teatro: Um manifesto de menos; O esgotado, Rio de Janeiro: Jorge Zahar Ed..

DERRIDA, J (1995), “O teatro da crueldade e o fechamento da representação”, In: A escritura e a diferença, São Paulo: Ed. Perspectiva. 
DIB, N. (2009), “O Teatro experimental da Socìetas Raffaello Sanzio”, Dissertação de Mestrado, São Paulo: ECA/USP.

DIDI-HUBERMAN, G (1998), O que vemos, o que nos olha, São Paulo: Editora 34.

DIDI-HUBERMAN, G (2012), Quando as imagens tocam o real, Revista do Programa de PósGraduação em Artes da Escola de Belas Artes da UFMG, v.2, n.4, 206-219.

DUBATTI, Jorge (2016), O teatro dos mortos: introdução a uma filosofia do teatro, São Paulo: Edições Sesc São Paulo, 204.

FÉRAL, Josette (2015), Além dos limites: teoria e prática do teatro, São Paulo: Ed.Perspectiva, 424.

FERNANDES, S. (2009), “Teatralidades contemporâneas", En: Texto e Imagem: estudos de teatro, Rio de Janeiro: Ed. 7Letras.

FERNANDES, S.(2009), Teatralidades do real, Revista Subtexto: Revista de Teatro do Galpão Cine Horto, número 6, dezembro, 37-38.

GERLAND, Oliver (1989), "Lyotard and the theatre of energy", in Irmengard Rauch, Gerald F. Carr (Org), The Semiotic Bridge: trends from California, Berlin, New York: Mouton de Gruyter, 21-32.

GUINSBURG, J (2001), Da cena em cena: ensaios de teatro, São Paulo: Ed.Perpectiva, 142.

GUMBRECHT, H. U (2010), Produção de Presença: o que o sentido não consegue transmitir, Rio de Janeiro: Contraponto/Editora PUC-Rio.

KRAUSS, R (2007), Caminhos da escultura moderna, São Paulo: Martins Fontes.

LEHMANN (2007), Hans-Thies, Teatro pós-dramático, São Paulo: Cosac Naify.

LEETEN, Lars (2015), Ética da receptividade: aspectos de uma filosofia moral segundo JeanFrançois Lyotard, In: Trans/Form/Ação, Marília, v. 38, n. 1, Jan./Abr, 133-146.

LOCKE, Kirsten (2013), “Anima Minima: Lyotard's Monstrous Infancy”, Kritikos: International and Interdisciplinary Journal of Postmodern Cultural Sound, Text and Image, Volume 10, April-May-June.

LYOTARD, Jean-François (1997a), “The tooth, the palm”. In: MURRAY, Thimothy. Mimeses, masochism \& mime, The politics of theatricality in contemporary French thought, Ann Arbor: The University of Michigan Press, 282-288.

LYOTARD, Jean-François (1997b), O Inumano, Lisboa: Editorial Estampa.

NANCY, Jean-Luc (2000), Corpus, Lisboa, Vega.

PELBART, P (2000), “Ueinzz- Viagem a Babel”, In: A vertigem por um fio: politicas da subjetividade contemporânea, São Paulo: Iluminuras/FAPESP.

RANCIÈRE, Jacques (2004), Aesthetics and its discontents, França: Editions Galilée.

REBENTISCH, J. (2016), O plural da arte. In: Revista do ARTIS - Instituto de História da Arte, Faculdade de Letras, Universidade de Lisboa, Portugal, n.4.

VERNANT, J; VIDAL-NARQUET, P (2005), Mito e tragédia na Grécia antiga, São Paulo: Perspectiva. 